\title{
A Questão Florestal na História da llha de Santa Catarina
}

Susana Cesco*

Resumo: O final do século XVIII e início do século XIX marcou um processo de intensas transformações na Ilha de Santa Catarina, ao sul do Brasil. Momento de reconhecimento das potencialidades econômicas e ambientais locais, de ocupação e consolidação da colonização europeia, iniciada meio século antes. É nesse período que a população da Ilha também impõe um novo ritmo nas transformações ambientais. A partir daí ocorre uma redefinição nos usos dados à floresta, ao mar e à terra da Ilha. Esse território insular, com fronteiras naturais definidas, sofre nesse período intensas mudanças que vão da derrubada da floresta para uso local e, mais importante, para uso da Real Armada Portuguesa. A análise dessas transformações da natureza e de suas influências na vida de uma sociedade permite uma leitura de novos ângulos da história local, considerando a questão ambiental como elemento essencial.

Palavras-chave: Transformação ambiental. Indústria madeireira. Progresso.

\footnotetext{
* Bolsista PRODOC no CPDA/UFRRJ, Doutora em História Social IFCS/UFRJ. E-mail: susanacesco@gmail.com. Universidade Federal Rural do Rio de Janeiro, Instituto de Ciências Humanas e Sociais, CPDA. Avenida Presidente Vargas, 417, $9^{\circ}$ andar. Centro, CEP. 20071-003 - Rio de Janeiro, RJ - Brasil, Telefone: (21) 2224-8577 Ramal: 232
} 


\section{Introdução}

As várias etapas da devastação da Mata Atlântica, que cobria praticamente todo o litoral do Brasil, inclusive a Ilha de Santa Catarina, foram mudanças ambientais causadas basicamente em cinco séculos de ocupação. Elas manifestaram efeitos, muitas vezes, inconscientes, provenientes de escolhas e de visões políticas que buscavam outros fins que não a devastação pura e simples. Essa inconsciência foi fruto do desconhecimento da floresta que se estava ocupando e transformando e de como ela reagiria a uma intervenção tão repentina. Não podemos esquecer que a Mata Atlântica é muito diferente das conhecidas florestas europeias dos colonizadores. A devastação desenfreada não era vista como um problema, pois desconhecia-se a dificuldade e demora da regeneração da mata. Quando as madeiras nobres começaram a rarear é que soou o sinal de alerta. A situação é similar a uma analogia que Maquiavel descreve em O Principe (MACHIAVELLI, 1999, p. 33) ao dizer que o mal é fácil de curar e difícil de reconhecer no princípio, mas, com o passar do tempo, não sendo no início conhecida e medicada a doença, torna-se fácil de reconhecê-la e difícil de curá-la. O mal causado à Mata Atlântica foi tardiamente reconhecido.

Nesse contexto, a proposta de uma análise histórica e ambiental da Ilha de Santa Catarina no final do século XVIII e século XIX passa pela necessidade de uma ampliação temporal para compreender mais profundamente causas e efeitos, questionando alguns pontos da história tradicional já escrita sobre o Brasil e a Ilha de Santa Catarina. Essa ampliação do foco vai ao encontro das palavras de John McNeill ao se referir às grandes mudanças ecológicas do final do século XIX e XX:

[...] em termos ecológicos, a situação atual se diferencia enormemente de qualquer status duradouro e mais "normal" que tenha caracterizado o mundo no curso da história do homem; para não dizer no curso da história da Terra. Se pudéssemos viver 700 ou 7000 anos entenderíamos simplesmente na base da experiência e da memória. Mas para seres que vivem uns 70 anos ou pouco mais é necessário o estudo 
do passado, recente e remoto para chegar a conhecer aquilo que entra no campo das possibilidades e do que é possível ser duradouro. (McNEILL, 2000, p. 461).

Seguindo essa premissa, a ideia desse estudo é de analisar grandes temas históricos pelo prisma da história local, em que importantes questões, como a indústria madeireira ou a produção e aclimatação de espécies exóticas - que geraram paisagens altamente devastadoras e lucrativas como os canaviais e os cafezais aqui mesmo no Brasil -, são considerados, mesmo que indiretamente, em sua relação com a história local. Usando o espaço restrito de uma ilha e os limites naturais impostos pela insularidade, pode-se perceber com mais clareza pontos que em outros lugares ficariam mais dispersos ou diluídos e, talvez de forma ainda mais contundente, o entrelaçamento de questões que normalmente são tratadas de forma isolada pela história.

A pesquisa de momentos políticos distintos, estratégias de colonização inovadoras - no caso da Ilha de Santa Catarina foi inovadora para os padrões portugueses - e visões diferentes dos atributos da natureza permitiram que se reconstituísse uma linha temporal do período proposto, analisando questões sociais e ambientais locais da Ilha de Santa Catarina, nosso objeto de estudo.

Considerando que os grandes sistemas sociais e culturais elaborados no curso da história terminaram, inevitavelmente, por promover amplas consequências sobre o ambiente vivido, não menos do que sobre os homens, verificamos que os modelos de colonização e ocupação do território brasileiro seguiram essa máxima. A política portuguesa para o sul do Brasil, especificamente, poderia ter gerado modelos mais amenos de ocupação da terra, pois estimulava a pequena propriedade, ao contrário dos grandes latifúndios monocultores, que transformavam grandes áreas antes cobertas de uma fauna e flora diversificada em tapetes de um mesmo produto exótico. $\mathrm{O}$ resultado, no entanto, ao menos no que tange à devastação florestal, não diferiu muito.

As questões globais analisadas em âmbito regional possibilitam a identificação, entre permanências e rupturas, de uma continuidade; por exemplo, nos métodos de extração da madeira, na preparação dos terrenos para a agricultura, na secagem dos pântanos e na 
derrubada das árvores ou nas queimadas. Por outro lado, verificamos, entre outras especificidades de viver em uma ilha, uma relação nova com o mar e com as praias, especialmente na segunda metade do século XIX. Esses tópicos, quando unidos e questionados como fazendo parte de um universo maior de transformações, trazem à tona a estreita ligação entre homem e meio ambiente e a ideia de progresso da época.

Principiando o estudo na última década do século XVIII, quando da publicação da carta régia assinada pela rainha Dona Maria I no ano de 1797, pode-se perceber o início de uma preocupação maior com o mapeamento das riquezas vegetais da então colônia de modo geral. De acordo com o texto, a Coroa requisitava a propriedade total, não só das espécies de "madeiras de lei", mas de todas as árvores existentes na faixa de 10 léguas (aproximadamente 66 quilômetros) da costa e das margens de "[...] rios que desemboquem imediatamente no mar, e por onde em jangadas se possam conduzir as madeiras cortadas até as praias" (SOUZA, 1934, p. 20-21). Essa medida afetava diretamente a Ilha de Santa Catarina, menos por sua aplicação real, que se seguida literalmente, transformaria a Ilha em propriedade exclusiva da Coroa, mas por uma maior observação do desflorestamento, tanto por parte dos políticos locais como de viajantes estrangeiros ou dos próprios ocupantes das terras.

Esses últimos anos do século XVIII foram prolíficos em matéria de leis para a conservação das matas do Brasil. O enfoque continuava sendo preponderantemente utilitarista, mas novas ideias de preservação já começavam a surgir. Aliado a isso, o crescimento comercial e a redefinição dos espaços urbanos e rurais na Ilha, principalmente em meados do século XIX, foram desencadeadores de uma grande metamorfose em hábitos e costumes dos homens, no meio ambiente e nas práticas cotidianas. A própria noção de progresso deixou de estar associada unicamente à necessidade de limpar a terra de suas matas para o povoamento e para o desenvolvimento agrícola e urbano. Passaram por debates políticos ou pela imprensa local questões como o controle da poluição, potabilidade de água e necessidade de espaços arborizados, esses sim os novos sinônimos de progresso de grandes cidades da Europa e dos Estados Unidos no século XIX. 
A legislação sobre a derrubada das matas proporcionou certo controle, ao menos na teoria, na exploração florestal. Estava definido o uso atribuído às melhores peças de madeira e, consequentemente, do que os habitantes locais poderiam dispor. Esse fato, aliado à facilidade da derrubada, provocou uma grande devastação nos mangues da Ilha, especialmente nos localizados próximos à vila e depois cidade de Nossa Senhora do Desterro, para uso nas caieiras e nos engenhos. A derrubada era fato nas proximidades da maioria das vilas e cidades do Brasil e esta análise permite lançar mais luz a um processo peculiar de transformação da paisagem e da vida social desse ponto do Brasil que foi uma parcela pequena de uma indústria madeireira insipiente em todo o território brasileiro nos séculos XVIII e XIX, mas que é, certamente, uma parcela da história da devastação da Mata Atlântica brasileira baseada na noção de progresso vigente.

Levando em conta essas abordagens, pode-se explorar como, no caso da Ilha de Santa Catarina, a natureza é colocada a "serviço" de projetos sociais, econômicos e políticos, fazendo uma análise das relações que esses projetos estabelecem com esse espaço, aqui entendidos ao mesmo tempo como realidade biofísica e produção cultural da ação humana (ARRUDA, 2000, p. 136).

\section{Uma história da floresta na Ilha de Santa Catarina: os fundamentos}

A Ilha de Santa Catarina, povoada escassamente até meados do século XVIII, longe, praticamente isolada da capital da colônia e com uma extensão territorial de $423 \mathrm{~km}^{2}$, tinha a Floresta Ombrófila Densa como formação vegetacional original. Era um local pouco explorado, com portos naturais protegidos e uma vila de pequenas proporções apta para a ocupação, colonização e aproveitamento. A Ilha ficou mais conhecida quando, nos anos finais do século XVIII e no início do XIX, sob a administração do Governador João Alberto de Miranda Ribeiro, sofreu um escrutínio no que tange às suas potencialidades econômicas e naturais, ou melhor, às possibilidades 
de transformar as potencialidades naturais em econômicas. Nesse período, através da rica correspondência do governador com o então Vice-Rei, Dom José Luiz de Castro, o Conde de Rezende, que esteve à frente do governo do Brasil de 1790 a 1801, pode-se mapear e analisar o processo de desmatamento na Ilha, as práticas agrícolas implantadas e o desenho populacional local. Essas informações fazem parte do conjunto documental que engloba a carta régia de 1797 e o relatório elaborado por João Alberto de Miranda Ribeiro no mesmo ano, em resposta ao Vice-Rei, que solicitava notícias sobre as potencialidades do território sob sua administração e um plano para uma melhor utilização desses recursos, em especial a madeira e os produtos agrícolas.

As informações fornecidas através de correspondência oficial dessas autoridades, entre vários pontos, enfatizam a variedade e a qualidade das madeiras existentes nessa porção do território brasileiro. Aliado a isso, estava a facilidade de exploração da mesma, tendo em vista a acessibilidade de portos para seu escoamento e transporte e o fato de os habitantes locais, fixados em terras sob a forma de sesmarias, já terem por contrato a incumbência de reservar as melhores madeiras para a Coroa Portuguesa. Essa prática era comum e foi encontrada em muitas cartas de doações de terras, sob o título de sesmarias, na Ilha de Santa Catarina, no século XIX, mais precisamente até 1823 . Exemplo disso é a concessão feita pelo Governador Joaquim Xavier Curado a Manuel Dutra Garcia de

[...] uma data de terras de duzentas e vinte braças de frente e quatrocentas e sessenta e uma de fundos, pelo lado Oeste, e pelo Leste com quatrocentas e trinta e uma, fechando a linha de fundo da parte Norte com duzentas e cinqüenta braças de extensão [...] no lugar vulgarmente chamado Costeira do Ribeirão. [...] e não compreenderá desta Data Vieiro ou Minas de qualquer gênero de Metal que nelas se descobrir, reservando também os Paus Reais e faltando quaisquer das ditas clausulam por serem conformes as reais ordens e as que dispõem a lei e foral da Sesmaria, ficará privado desta. (CURADO, 1804) 
Efetivamente, as transformações ambientais destrutivas foram aceleradas com a chegada repentina de muitas pessoas provindas do Arquipélago dos Açores e da Ilha da Madeira, ainda em meados do século XVIII. Porém, um interesse mais concreto na preservação ou separação das matas que poderiam ou não ser usadas livremente se deu pela carência de madeiras nobres para a construção naval, atividade que se ficasse ameaçada por falta de matéria-prima colocaria em risco a própria soberania portuguesa. É nesse momento, já no apagar das luzes do século XVIII que a legislação portuguesa que ordenava o corte de madeiras em terras brasileiras promoveu uma eleição de qualidade dentro das florestas que ainda cobriam o Brasil e, entre elas, a Ilha de Santa Catarina. Nessa eleição, os grandes prêmios - as madeiras reservadas ou, posteriormente, designadas como madeiras de lei-não mais poderiam ser usadas pela população local para suas caieiras, seus engenhos, suas habitações ou qualquer outra utilidade a que estavam vinculados, deveriam sim ser destinados a fins mais nobres como a construção de navios de guerra para a Real Armada Portuguesa.

Embora as disposições legais de ordenação do território fossem frequentemente burladas e os relatórios que deveriam ser produzidos pelos governadores para atender as exigências da carta régia de 1797 nem sempre fossem feitos, ou feitos com correção, as instruções quanto ao escrutínio das potencialidades econômicas da natureza e da sociedade locais foram diligentemente cumpridas, particularmente pelo governador de Santa Catarina. O resultado foi a produção de documentos sobre a quantidade, qualidade, localização e disponibilidade das principais madeiras locais, juntamente com tabelas de exportação desse e de outros produtos agrícolas implantados nos locais que ocuparam as áreas de floresta desmatada. Aliás, a Carta Régia só serviu como indicativo de complementações a serem feitas pelo dito governador, uma vez que o Conde de Rezende, em carta ao Ministro Rodrigo de Souza Coutinho, em três de dezembro de 1797, afirma já estar de posse de algumas relações que lhe foram dirigidas pelo governador da Ilha de Santa Catarina e outros oficiais incumbidos de, a seu pedido, fazer uma visita aos territórios da dita capitania e produzir um relatório, muito antes da Carta Régia ser editada (CAVALCANTI, 2004, p. 257). 
O projeto oficial de extração de madeiras na Ilha de Santa Catarina apenas acentua-se quando o Conde de Rezende, seguindo as disposições da já citada carta régia, solicita ao Governador da Ilha e dos demais Distritos de sua Jurisdição, um relatório sobre a qualidade e quantidade de madeiras de construção e viabilidade de tal empreendimento. Pedidos de informações que, possivelmente, foram encaminhados a todos os governadores foram seguidos de outros ainda no ano de 1797, como o ofício datado de 18 de setembro em que era solicitado ao governador, de forma sigilosa, "[...] hum Mapa da extração de todos os gêneros que no ano de 1792 sahirão dessa Ilha" (CONDE DE REZENDE, 18/09/1797) com declaração da quantidade, dos nomes dos portos para onde foram enviados, preço médio e valor total. O Vice-Rei prevenia que seriam necessárias as mesmas informações para os anos posteriores, de 1793 a 1796 e do ano em curso, 1797, por fim, solicitava o envio mensal de uma relação da farinha e dos demais gêneros de primeira necessidade existentes nos domínios do governador.

Existia aqui uma dificuldade no cumprimento das ordens, especialmente a última delas, uma vez que a correspondência entre o Rio de Janeiro e as demais Capitanias era feita por navios que estivessem de passagem entre ambos os portos e cujos capitães fossem considerados de confiança. Isso geralmente demorava alguns meses para acontecer, como acusam as respostas do governador com alusão às datas de recebimento.

No que tange às madeiras, o primeiro ofício do Vice Rei para o governador com conteúdo específico data de 27 de outubro de 1797 e inicia com a sugestiva afirmação de que o " [...] corte e prontificação das madeiras chamadas de construção" era tema que, em função da conjectura atual, merecia mais atenção" (CONDE DE REZENDE, 27/10/1797). O tom desse documento está na recomendação de envio

[...] não só nas avultadas remessas de taboados de Tapiunhoam, Peroba e Vinhático, mas também hu'a exata informação dos lugares em que há matas e arvoredos da quella qualidade; de modo de as conservar e promover a sua cultura; e dos sítios mais aptos para se estabelecerem os cortes das que forem precisas para a referida marinha. (CONDE DE REZENDE, 27/10/1797) 
A importância do tema reflete-se nas providências que o ViceRei se propõe a tomar, citadas no mesmo documento, certamente guiado por instruções da Coroa e do Ministro de Assuntos Ultramarinos. O Conde de Rezende propunha-se a enviar uma verba anual para estabelecer cortes de madeira na Ilha e nos demais domínios de Santa Catarina. Para tal, solicitava uma relação individual dos lugares mais cômodos para o estabelecimento dos cortes baseados na abundância de madeiras e facilidade de sua exportação. Outro dado solicitado era se existia a possibilidade de, nos portos locais, construírem-se embarcações capazes de transportar essas madeiras para Lisboa ou se, do contrário, poder-se-iam carregar os ditos taboados fora da barra. Aliado a isso, questionava sobre a existência na cidade de alguns construtores, aos quais seriam pagos soldos para tal.

O tema das madeiras estava tão em alta que, aparentemente, o próprio Vice-Rei estava sendo cobrado para obter informações sobre o mesmo. Também o fato de até então não ter recebido respostas do governador fizeram-no reforçar o pedido em 03 de dezembro de 1797. Nesse novo ofício, ele ordena que o governador "[...] ponha em prática o reconhecimento das matas em que logo se deve estabelecer serrarias, apenando para este fim todos aqueles trabalhadores que forem precisos." (CONDE DE REZENDE, 03/12/1797) O conde ressaltava a economia que se deveria fazer em tal empreendimento, sugerindo inclusive o uso dos soldados que não fossem necessários para o serviço diário, para esse trabalho com as madeiras. Esses soldados receberiam pagamento por isso além do seu soldo regular. Para viabilizar os trabalhos, o conde mandaria todas as ferramentas que se fizessem necessárias.

Para finalizar o ofício, o Vice-Rei lembrava que ainda aguardava as informações solicitadas no ofício de 27 de outubro de 1797 e não poderiam ser deixadas de lado em função do presente ofício. Ambas eram prioridades. Essas cobranças do Vice-Rei para com o governador possivelmente eram reflexos das cobranças do Rei e dos ministros para com ele próprio. Uma rede de homens que, no desempenho de suas funções políticas e diante da necessidade de apresentar resultados, deparava-se com questões que seriam mais facilmente resolvidas pela experiência de roceiros ou bandeirantes. Esses conhecimentos e reconhecimentos de árvores, caminhos e 
gêneros agrícolas careciam da opinião de assessores locais, dos mais rudes e simples, que eram consultados antes da elaboração de relações de madeiras ou de produção agrícola. Aliado a isso encontrava-se a instabilidade do cargo de governador que muitas vezes durava um ou dois anos, algumas vezes, meses, período não suficiente para se inteirar dos assuntos dos predecessores e para conhecer as potencialidades de seus domínios. Tudo isso poderia ser um desestímulo para a realização desses levantamentos que não eram simples, pois dependiam de uma rede de funcionários e informantes.

A primeira informação diretamente ligada a esse tópico se dá em fevereiro de 1798, quando, a pedido do governador, Valentim Antonio Vilela envia a relação da farinha e da lenha consumida pelos armazéns reais, pelas fortalezas, prisões, praças avulsas e reformadas e pelos índios a serviço da Ribeira. A farinha totalizou um consumo de 5.658 alqueires por ano e a lenha 5.448 feixes por ano. É importante lembrar que dois anos antes, de acordo com tabela do governador, exportou-se 28.333 alqueires de farinha de mandioca. Já o custo do consumo de lenha alcançava 280\$000 mensal e 3.360\$000 anual para a Fazenda Real (VILELA, 26/02/1798). Se analisarmos esses dados comparativamente, percebemos que apenas o consumo de farinha por parte dos homens da ribeira, das fortalezas e prisões sob responsabilidade do governo, era superior a 1/6 das exportações desse produto pela Capitania. Essa cota de manutenção era uma obrigação dos agricultores locais, que deveriam receber do governo por esses produtos, o que muitas vezes não acontecia. Daí compreende-se a redução na própria produção de farinha na região, já que a quantidade destinada às tropas era uma porcentagem da produção total. Menos produção, menor a parcela dada à manutenção das tropas. O mesmo ocorria com a lenha (RIBEIRO, 17/11/1797).

Em 20 de março de 1798, o governador de Santa Catarina enviou as primeiras providências tomadas em resposta aos ofícios do Vice-Rei. O mesmo mostrou-se satisfeito e enviou novas solicitações, especialmente no que se refere aos jornais pagos aos artífices, carpinteiros e toda a sorte de trabalhadores a serem envolvidos nos trabalhos. A regra era sempre pagar o mínimo possível. Em outra resposta, em oficio datado de 22 de março de 1798, o Governador afirma que 
[...] depois de bastantes, averiguações tenho podido alcançar, que talvez seja quanto baste, para dar inicio aos bem fundados projetos de V. Ex ${ }^{a}$, não só sobre o corte das Madeiras, que pretende mandar estabelecer nesta Ilha, mas ainda para a construção de algumas embarcações que na mesma se fabriquem proporcionadas para as conduzirem deste porto para o de Lisbôa. Posso segurar a V. Ex $x^{a}$, que tenho encontrado bastantes lugares, com todas as comodidades, e circunstancias necessárias para se construírem as referidas embarcações de onde estas ao depois de feitas sem que se possa temer o menor prejuízo, se podem lançar do estaleiro ao Mar, e da mesma forma serem carregadas pela Barra a fora sem embaraço algum. Pelo que diz respeito ao corte e condução das madeiras para o Estaleiro (segundo as informações que se me tem dado) não será muito dificultoso (RIBEIRO, 22/03/1798).

O Conde de Rezende enfatiza em ofício de 03 de setembro de 1798 que o governador deve coibir o que chama de liberdades dos moradores, que dispunham livremente das madeiras das áreas de mata em suas posses. Essa prática deveria ser totalmente vetada não só no que se refere às madeiras proibidas como todas as que se julgarem próprias para a construção de embarcações e para aduelas ou qualquer outro destino importante à Fazenda Real.

Por ser ponto estratégico nas rotas de navegação sul-americanas dos séculos XVIII e XIX e ponto intermediário entre Buenos Aires e Rio de Janeiro, a Ilha também possuía portos acessíveis para o escoamento da madeira, aliado aos baixos preços da extração e o alto lucro obtido na chegada tanto no Rio de Janeiro como em Lisboa. A madeira era um grande negócio para a Fazenda Real Portuguesa e na costa catarinense era encontrada em seu litoral pouco desbravado, diferente do Sudeste e Nordeste, cujas porções litorâneas já estavam de muito tomadas por grandes plantações e a madeira e lenha para o abastecimento já vinha muito do interior, dificultando o escoamento.

Além dessa facilidade, poder-se-iam construir embarcações para o transporte dessa madeira na própria Ilha. Em carta de 12 de agosto de 1800, o Engenheiro Intendente da Marinha José Caetano 
de Lima reafirma ao Vice-Rei Conde de Rezende informações que o Governador João Alberto de Miranda Ribeiro havia fornecido há um ano. $\mathrm{O}$ engenheiro relata a existência de lugares com todas as comodidades para se construírem as ditas embarcações (LIMA, 12/08/1800), outro facilitador do empreendimento, uma vez que tudo se resolveria localmente: matéria-prima, mão de obra e transporte.

A construção das embarcações para a Fazenda Real ficaria a cargo do Construtor Agostinho Francisco que estava atuando na Ilha em construções particulares. Se essa ideia fosse aprovada, seria necessário que o Vice-Rei enviasse planos e riscos de embarcações vindos de Lisboa, reafirmação de que era um empreendimento real e cuja responsabilidade sobre tal era da Coroa, materiais locais só a madeira e a mão de obra. $\mathrm{O}$ restante do material necessário à construção, como ferragens, também viriam de Lisboa ou do Rio de Janeiro. De posse dos tais desenhos, o construtor faria as alterações necessárias e indicadas pelo Vice-Rei no que se refere ao aumento ou à diminuição dos tamanhos das embarcações.

Em outro ofício, de 11 de abril de 1798, o governador relata que:

Hoje mesmo mandei oito machados para o mato deitar abaixo todas as perobas for possível enquanto favorecer este corte o minguante da lûa em que estamos: e para a semana que vem mando as serras para serrarem a taboa de como no referido officio n ${ }^{\circ} 17$ digo a V. Ex ${ }^{a}$. Aqui não há tapinhõas, nem vinhoties ou para melhor dizer são todos raros esses paos, que com muita dificuldade se encontra hum, ou dous, depois de se ter caminhado pelo mato hum grande espaço de terreno. O mestre construtor de quem eu falei a V. Exa no meu officio $\mathrm{n}^{\circ} 11$, me afirma, que as melhores madeiras que há nesta Ilha para a construção dos navios, são a Massaranduba, a Canela burra, e ainda a preta, e havendo destas três qualidades e quantidade suficiente, me parece que se deviam aproveitar, porque ainda que não excedão a Peroba, e as outras que não há como diz o referido construtor, basta só igualarem para ficarem admiráveis. (RIBEIRO, 11/04/1798) 
No início do século XIX, a extração de madeira na Ilha de Santa Catarina, especialmente louro preto, cedro vermelho, óleo vermelho, canela preta, ipê, peroba vermelha, canela burra e massaranduba, já eram destinados exclusivamente à construção naval da frota da Real Armada Portuguesa. Essas madeiras foram indicadas em 1798 como preferenciais por Agostinho Francisco da Silva e Simplício Jozé Rodrigues, mestres construtores da Ribeira, no Rio de Janeiro, consultados sobre o tema pelo Vice-Rei.

Essa nascente "indústria madeireira" na Ilha de Santa Catarina tinha outra vantagem para a Fazenda Real. As espécies acima indicadas não faziam parte das ditas madeiras reservadas, posteriormente chamadas "madeiras de lei" e seria lucrativo retirá-las das terras concedidas em sesmaria e que estivessem em situação ilegal por não terem cumprido a obrigatoriedade de produzir e construir benfeitorias em prazo de dois anos. $\mathrm{O}$ interesse da coroa não era desalojar de todo esses "proprietários", mesmo em situação ilegal, já que quanto mais ocupado o território menor o risco de invasão e ocupação estrangeira. Por outro lado, poder-se-ia tirar proveito das eventuais irregularidades, uma vez que as madeiras não reconhecidas como reservadas ou de lei, deveriam ser pagas aos ocupantes legais do terreno em caso de extração por parte do governo. De acordo com João Alberto de Miranda Ribeiro:

Estas ultimas madeiras sabe V. Ex ${ }^{a}$ muito bem que não são reservadas: por isso elas podem ser logue que V. Ex assim o ordene, ou pelos menos elas se podem cortar sem que se paguem aos donos das terras que as produzem: porque Sua Magestade lhes deo gratuitamente as terras, com a condição de as cultivarem dentro de certo tempo limitado, e claro está, que tendo faltado a esta condição, até parece que a posse não deve ter validade alguma. Finalmente eu me persuado que logo que Sua Magestade caresa de Madeiras de qualquer qualidade que elas sejão, as deve mandar cortar, sem que pela sua Real Fazenda as mande pagar áqueles mesmos vassalos, a quem concedeo as terras. (RIBEIRO, 11/04/1798) 
Sendo essas madeiras de alto valor naval e estando os sesmeiros na ilegalidade, não seria necessário pagar-lhes por tais madeiras, sob a ameaça de desapropriação das terras que voltariam a ser devolutas, possibilitando mais lucros à Fazenda Real. As madeiras apontadas pelo governador nesse caso eram a massaranduba (Mimusops elata), a canela burra (Ocotea urbaniana) e a canela preta (Laurinia atra). Outra vantagem era que os próprios ranchos e seleiros construídos para a estocagem da madeira, próximos aos embarcadouros, poderiam ser feitos com grande economia, sendo a maior despesa destinada à compra de telhas.

De acordo com as inspeções de engenheiros navais, relatórios de juízes conservadores ou simplesmente por indicação de qualidade feita por mestres construtores escolhidos pela Coroa, designavam-se as espécies mais apropriadas para a construção naval. Em âmbito nacional, as madeiras mais importantes eram: sucupira (Pterodon amarginaturs), canela (Ocotea catarinensis Mez), canjarana (Cabralea canjerana), jacarandá (Nissolia legalis), araribá (Centrolobium robustum), pequi (Caryocar braisiliensis Camb), jenipaparana (Gustavia Augusta L.), peroba (Aspidosperma ramiflorum), urucurana (Hyeronima Alchorneoides Fr. All.) e vinhático (Plathymenia reticulata). (RIBEIRO, 11/04/1798) ${ }^{2}$ Essa lista, que não era oficial nem destacava todas as madeiras boas para construção naval, era um apontamento geral de algumas das árvores, sendo que os nomes poderiam mudar de acordo com as especificidades regionais. Uma lista produzida com base nas indicações de mestres construtores da Ilha de Santa Catarina foi enviada ao Vice-Rei pelo governador em sua correspondência oficial, nela indicava-se, entre as de maior valor local, a tapinhoã (Mezilaurus navalium), que era classificada em primeiro lugar porque resistia aos parasitas marinhos.

Já sob o governo de Joaquim Xavier Curado, que assumiu após a morte de João Alberto de Miranda Ribeiro, em 1800, o Conde de Rezende reforça as disposições sobre a madeira e manda embarcar tudo o que estiver pronto desse material e também aquele que possa servir para reparos. (CONDE DE REZENDE, 14/06/1801) O mesmo repete-se no ano seguinte, já com D. Fernando José de Portugal como Vice-Rei. É também nesse ano que o novo ViceRei solicita que o Governador siga as orientações enviadas por ele 
e mande construir uma embarcação. A lista dessas madeiras e de seus cortes tinha 74 itens, ou seja, 74 tipos de cortes de madeira em quantidades diferentes para a construção de uma Nao.

Quanto à extração de madeira das propriedades privadas, empreiteiros eram enviados pelo governo com tal função. Dificilmente as madeiras não selecionadas eram poupadas de danos, pois não existia uma preocupação real com isso, o mesmo pode-se dizer das árvores de menor porte que muitas vezes eram derrubadas na esteira das maiores e ficavam pelo chão como lixo. No caso de derrubada das "madeiras reservadas" por parte dos proprietários, era necessária uma autorização prévia (DEAN, 1996, p. 153). Em Santa Catarina, essa informação sobre construção naval ainda fazia parte do relatório do agora "Presidente da Província" João Carlos Pardal, em 1838, quando afirmava no tópico 'indústria fabril' "a construção de poucos navios de mais de cem toneladas, e de outros de menor porte." (PARDAL, 1838, p. 16) Ainda de acordo com o mesmo presidente da Província, as madeiras, abundantes nas matas catarinenses, não concorriam para o aumento da indústria comercial por falta de uma inspeção mais rigorosa e presidida por "homens científicos", apesar de que, de acordo com Pardal, este ramo de comércio ainda seguia algum desenvolvimento.

Essas indicações de uso, qualidade e proibições sobre as madeiras seguem noções e juízos de valor totalmente ligados à época em que estão sendo elaborados. Por isso, a dinâmica desse processo de transformação passa pelos usos atribuídos à madeira nesses diferentes períodos da história e o grau de ocupação humana em cada local. Tal riqueza madeirável e a forma como foi utilizada está diretamente relacionada à forma como foi percebida. Uma paisagem tem um variado número de componentes e, dentre eles, cada cultura entende por "recurso" algo diferente. Depreende-se que "a paisagem natural é, portanto, o sistema de orientação simbólica de um povo e a sua projeção simbólica na sociedade" (CENCINI, 1999, p. 290). Para a população média da Ilha de Santa Catarina do início do século XIX, essas madeiras eram recursos, mas de uso restrito para eles como agricultores - função para a qual a maioria desses habitantes estava destinada desde a chegada ao local como imigrantes. Essas madeiras, quando extraídas, se dessem lucro, seria 
muito bom, mas era a agricultura que ocuparia seu lugar, seu objetivo maior. Por isso o fim dado à floresta não era tão importante. A ideia de desenvolver, planejadamente, uma indústria madeireira fazia parte do universo dos administradores portugueses; para os habitantes locais, a madeira e sua derrubada eram fases do processo de transformação da terra em solo agricultável.

Enfim, a Ilha de Santa Catarina entra no século XIX com certo controle, ao menos na teoria, da exploração de suas matas. Estava definido o uso atribuído às melhores peças de madeira e, consequentemente, do que os habitantes locais poderiam dispor. Nesse ínterim entram as especificidades locais e a experiência empírica que situa a floresta como importante em pontos que só o dia a dia pode delimitar. Surgem então ferramentas, como os textos legais para criar novas fronteiras de uso desses elementos. Em Desterro identificou-se, possivelmente depois de muitas experiências e erros, que essas mesmas matas tinham outra função importante que não estava sendo respeitada. Por conta disso, o capítulo sétimo do código de posturas do município, de 1845, dá conta de questões ligadas ao desmatamento e sua estreita relação com o abastecimento de água. O texto do capítulo I desse código declarava que

[...] os que derrubarem mattas nos lugares onde passem nascentes de agoa para as fontes publicas, ou ahi fazerem roçadas incorrerão na pena de $15 \$$ reis de condemnação. Os que lançarem immundicies nas sobreditas nascentes incorrerão nas mesmas penas, e no dobro reincidindo. Não tendo, porem com que pagar, sofrerão por cada mil reis um dia de prizão. ${ }^{3}$

Outros artigos desse mesmo código de posturas referiam-se às punições aplicadas a crimes que envolvessem a floresta. Dentre eles destacam-se o artigo 131, que proibia o corte de madeiras na beira das estradas e nos caminhos, exceto nos lugares úmidos, não só para maior conforto dos viajantes como para evitar que as derrubadas danificassem os caminhos. Já o artigo 53 definia multa de $8 \$ 000$ réis aos que queimassem matas ou retirassem madeiras em campos baldios ou logradouros públicos abertos. 
Paralelo à extração de madeiras consideradas nobres e cujo destino primeiro era a construção naval e, posteriormente, habitações, móveis, pontes e carros, outro ecossistema sofreu grande degradação na Ilha de Santa Catarina e no Brasil, de modo geral: os mangues. Compostos de árvores de menor porte e mais fácil extração, cuja casca era rica em tanino e, geralmente, localizados próximos dos centros urbanos, uma vez que esses se concentravam na costa, os mangues eram uma reserva acessível e rica e sua exploração, até a segunda metade do século XIX, ainda era vista como altamente benéfica. $\mathrm{O}$ mangue era sinônimo de doenças e miasmas para as populações em suas proximidades.

Segundo Arthur Soffiati, a reação inicial dos europeus quanto aos mangues foi de desprezo e afastamento por esse apresentar semelhanças com os pântanos de seu continente, considerados insalubres e povoados de entes malignos. Progressivamente, porém, as camadas sociais dominantes descobrem o seu valor como excelente fornecedor de madeira, lenha e tanino (SOFFIATI NETTO, 2004, p. 10). A percepção da utilidade dos mangues vem do saber indígena e popular, repassado aos europeus e consolidado desde os primeiros anos de colonização. Esse saber, se não levava ao reconhecimento dos mangues como ecossistema e com ele todas as suas peculiaridades, sua flora e fauna e a importância de preservar, ao menos ampliava a percepção de suas possibilidades e indicava sua diversidade. Tal fato pode ser constatado quando André João Antonil, ao falar dos mangues, os classifica como brancos e vermelhos, sendo o carvão obtido com a lenha do mangue branco, dos cajueiros, das aroeiras e das gameleiras o melhor para fazer decoada "[...] porque os paus fortes fazem mais carvão do que cinza, e a lenha miúda dá pouca cinza e sem força" (ANTONIL, 1976, p. 117) Assinala ainda que o mangue é um bom fornecedor de barro para olarias.

Tal utilidade e importância somada à manutenção da produtividade pesqueira do litoral, como berçário de inúmeras espécies de peixes, na estabilidade geomorfológica costeira, limitando a erosão marinha e a morfogênese, demandou legislação apropriada, especialmente no que se refere ao mangue vermelho. Contrariamente às disposições de preservação dos mangues, o código de Posturas 
do Município de Desterro de 1845, em seu capítulo 1, artigo 74 fala do uso dos mangues e indica que

[...] todo aquele que embaraçar a tirada de lenha dos mangues onde o povo deste Município está em uso de tiral-a, sem que tenha mostrado, à Autoridade competente, que taes mangues lhe pertencem por afforamento ou qualquer outro titulo, sera multado em $12 \$ 000$ reis, para despesas do conselho, e no duplo em caso de reincidência, alem da pena de desobediente $e^{4}$.

Esse fato, aliado à facilidade da derrubada, provocou uma grande devastação também nos mangues da Ilha, especialmente os localizados próximos a Desterro, para uso nas caieiras e nos engenhos. A derrubada era fato nas proximidades da maioria das vilas e cidades do Brasil. Relatórios governamentais indicavam que "[...] não existia mais madeira adequada por muitas léguas nas proximidades das vilas maiores [...] em Campos, as toras tinham de ser arrastadas de três a nove quilômetros até a costa." (DEAN, 1996, p. 152) Na Ilha, os mangues do Itacorubi e Ressacada foram reduzidos consideravelmente. Sua utilidade não era percebida como extrapolando a extração das cascas ricas em tanino e das madeiras baixas e de fácil exploração. Além do mais, a eles eram atribuídos boa parte dos miasmas da vila e a derrubada de sua vegetação os exporia ao sol e, ato contínuo, secaria seus lodaçais e eliminaria os mosquitos e o mau cheiro. Mais uma vez, o legal passou à margem do usual.

\section{Usos e Abusos: a transformação florestal da Ilha de Santa Catarina}

Em contraste com os europeus que haviam colonizado a América temperada - os quais, com efeito, encontraram florestas e árvores bastante semelhantes àquelas que eles haviam deixado para trás - os portugueses depararam-se, no processo de ocupação do território, com uma flora que lhes era nova em grande medida. Transformar esses elementos em recursos úteis à economia e à 
sociedade luso-brasileira foi um processo extremamente lento. A seleção de madeiras para qualquer aplicação requeria a consideração de muitos fatores e demoravam-se algumas décadas no método de tentativa e erro até que a espécie certa para um determinado emprego fosse encontrada. Além disso, a variedade de espécies vegetais e o pequeno número de indivíduos de uma mesma espécie em uma determinada área constituem os aspectos mais notáveis das florestas pluviais tropicais.

As madeiras da Ilha de Santa Catarina, reservadas ou não, foram largamente utilizadas para os mais diversos fins. Não diferenciando-se da Europa no que diz respeito aos usos básicos da população. Desterro usava madeiras para construção de habitações, igrejas, pontes, móveis, veículos e tantos outros usos corriqueiros que não poderiam ter substitutos a altura. Mesmo as construções de alvenaria ou pau a pique demandavam madeiras, pois os tijolos e telhas eram feitos em fornos abastecidos de lenha. Evidentemente que as espécies usadas para esses diferentes objetivos variavam de acordo com o poder aquisitivo das pessoas e com os préstimos e as qualidades atribuídas à madeira.

Os préstimos das madeiras variavam muito. Massarandubas e canelas ornavam casas mais abastadas como a casa do Governador e quem sabe de outros ricos locais. O mangue branco era uma melhor matéria-prima para o carvão. O mangue vermelho era a base - mais especificamente as cascas das árvores desse mangue - de fornecimento de tanino para curtumes, motivo pelo qual, como indicado anteriormente, gerou uma legislação voltada à sua preservação, legislação essa que não chegou especificamente à Santa Catarina nesse período. A consequência disso foi que os ricos mangues que, em sua maioria localizavam-se ao norte e ao sul da vila de Desterro, fossem também explorados para fins de combustível de engenhos de farinha. Aliás, esse foi o fim de muita madeira da Ilha de Santa Catarina.

Por conta disso, consideramos que efetivamente existiu uma indústria madeireira na Ilha de Santa Catarina, porém é preciso dimensionar seu tamanho e importância em relação às restrições de tamanho da própria Ilha que, consequentemente, restringia também a disponibilidade de madeira sobre seu território. 
Podemos concluir que, com o passar das décadas do século XIX, muita experiência foi adquirida, especialmente pelos moradores da Ilha. A lei de terras de 1850 encarregara-se, em nível formal, de normatizar a ocupação territorial no Brasil e, na Ilha, local já delimitado pelo mar, a necessidade de aproveitar melhor a terra passou a ser mais palpável. A agricultura, tão estimulada no inicio do século e uma das grandes responsáveis pela transformação de áreas de floresta - que davam lugar a campos cultivados e domesticados pelo homem - passa a dividir essa função com a expansão urbana. Desterro não é mais o único aglomerado urbano significativo da Ilha, as freguesias do interior também crescem no ritmo do crescimento populacional. Nesse compasso, crescem as casas, ampliam-se áreas construídas e, para se fazer isso, continuava-se a utilizar a matériaprima florestal. Floresta essa que não era mais a mesma de 60 ou 70 anos atrás. Pontos antes tidos como de difícil acesso, desvalorizados para a agricultura por serem íngremes ou pantanosos, já abriam os braços para casas comerciais e sobrados residenciais. O morro do Antão, nas costas do Hospital de Caridade, a praia de Fora, um pouco afastada do centro, todos já haviam sido ocupados pela nova vida urbana florescente em diferentes graus.

Uma nova percepção, surgida talvez da experiência, indicava novos atributos à floresta e um ponto que passou a ser também constantemente destacado pela imprensa e por autoridades locais era o bom uso da água e sua necessária ligação com a preservação de áreas de mata. Exemplo disso deu-se em 1860, quando a Câmara pedia que se tomassem providências para diminuir o desmatamento do morro que envolve a cidade, pois ele seria a causa da crescente escassez de água que afligia a população. Foi nesse mesmo ano que se iniciou o comércio de água em Desterro (ALMEIDA, 2003, p. 69).

O código de posturas de Desterro do final do século XIX, mais precisamente 1888, também destinava ações objetivando a preservação florestal. Acreditamos que essas atitudes se deram em resposta aos problemas observados nas últimas décadas, que testemunharam uma queda preocupante na área verde da Ilha. Esse Código Municipal de Posturas, elaborado pouco mais de 40 anos depois do anterior, que era de 1845 , tinha um capítulo dedicado à Hygiene e saúde pública e um subcapítulo que versava sobre as mattas 
e vallas. Independente do cumprimento ou não das disposições do código - aliás, pouco realmente se fez, haja vista a cobertura florestal atual da Ilha de Santa Catarina - proibiu-se o corte do mangue nos terrenos pantanosos ou alagadiços, exceto os existentes nas margens dos rios navegáveis, para desobstruí-los - essa foi uma mudança importante se compararmos esse código ao anterior. A proibição da derrubada das matas e dos capoeirões no morro a leste da cidade estendia-se para uma área de 50 braças para o lado da cidade e 20 braças para o lado oposto. O não cumprimento dessas normas implicava uma multa de $20 \$ 000$ a $30 \$ 000$ réis. Também era proibido extrair madeira ou lenha de qualquer qualidade na mata fronteira à cidade.

Claro está que, no último quartel do século XIX, já havia problemas de falta de lenha e madeira no entorno da cidade de Desterro e eram necessárias leis e punições para normatizar a continuidade na exploração desse material. O código de posturas também proibia o corte de árvores, a fabricação de carvão e as queimadas às margens de rios até a distância de 40 metros, outro indicativo da necessidade de preservar a cobertura florestal das margens ou o que sobrou dessa cobertura foi reiterada depois de, aproximadamente, 100 anos. Por outro lado, Vieira da Rosa indica, em 1905, a existência, ainda, de matas virgens em morros e várzeas da Ilha (VIEIRA DA ROSA, 1905 , p. 182), já o centro da cidade, segundo João Ribeiro de Almeida, em 1864, era totalmente desarborizado, e isso, se remediado, poderia evitar muitos males

$[\ldots]$ nem ao menos uma alameda se depara em Desterro [...] o que custaria o plantio e conservação de algumas dezenas de árvores frondosas, nas praias e praça? [...] E entretanto que somma de benefícios de que se deixa de tirar proveito! Seria lindo e utilíssimo. As plantações na opinião do illustre Mr. Chevreud constituem um meio de tornar salubre e purificar o solo, pois que as árvores não podem crescer sem que neles sorvão os materiais alteráveis, causa próxima ou remota da infecção. (RIBEIRO DE ALMEIDA, 1864, p. 77) 
A Ilha de Santa Catarina, apresentada não mais como um tapete verde de matas intransponíveis, já aparecia em descrições no final do século XIX e início do século XX, nas palavras do padre Vicenzi, como possuidora de colinas matizadas de verde mas "[...] notava-se, aqui e acolá, nas alturas menos íngremes, e não as mais elevadas, bonitos pedaços de terras, cuidadosamente cultivada." (VICENZI, 1904, p. 14) Essas palavras reforçam a imagem de uma Ilha diferente da encontrada pelos naturalistas estrangeiros no início do século XIX, mas também indicam que essas mudanças ainda estavam em andamento. Os problemas que no início do período imperial iam da exploração madeireira e da "necessidade" de ampliação da área urbana alcançando chácaras e sítios nos arrabaldes de Desterro, agora estavam concentrados na emergência do controle do desmatamento nos morros do entorno da cidade para evitar problemas de abastecimento de água e no controle do desmatamento e da coleta de lenha, novamente em áreas próximas à cidade, devido à escassez. Aquela floresta imensa, apesar das proporções geográficas da ilha serem limitadas, já estava reduzida e localizada nos morros mais elevados e em pontos de mais difícil acesso, alguns desses locais eram no interior da Ilha, graças às ruas e caminhos precários.

Desterro já era uma importante cidade, palco de embates políticos e cujas lutas anteriormente travadas para domesticar as matas e extrair riquezas do solo por elas coberto já eram temas do passado, apesar de um passado não tão distante. A extração de madeira para a Real Armada Portuguesa, que rendeu tantos documentos, cartas e relatos, aliados ao desenvolvimento da agricultura com seus manuais e estímulos para a aclimatação de plantas exóticas, já cedia espaço à questões de caráter político-administrativo, essa sim a nova vocação de Desterro, logo depois Florianópolis.

\section{The Forest Question in the History of the Island of Santa Catarina}

Abstract: The end of the $18^{\text {th }}$ century and beginning of the $19^{\text {th }}$, witnessed a
process of intensive changes on the island of Santa Catarina, southern Brazil.
Period of recognition of the economic and environmental potentialities of the
site and of the occupation and consolidation of European colonization which
started half century before, it is also in this period that the island's population 
imposed a new rhythm to environmental changes. From this moment on, a shift occurs in the use given to island's forest, sea and land. Its territory, which has defined natural boundaries, suffered, at that moment, from severe changes spreading from forest cutting for local use and, more importantly, to the Portuguese Royal Navy use. The analysis of these changes in the nature and of their influences on the life of a society allows new angles to read local history through, considering the environmental issue as an essential element.

Keywords: Environmental Change. Lumber Industry. Progress.

\section{Notas}

${ }^{1}$ Veio de ouro.

${ }^{2}$ As referências usadas para obtenção dos nomes científicos das plantas são: LORENZI, Henri. Árvores Brasileiras: manual de identificação e cultivo de plantas arbóreas nativas do Brasil. Nova Odessa: Editora Plantarum, 1992. Disponível em: www.umbuzeiro.cnip.org.br. Acesso em set. 2006.

${ }^{3}$ Código de Posturas da Câmara Municipal da Capital da Província de Santa Catarina. Nossa Senhora do Desterro, 10 de maio de 1845. Artigo 71, p. 226.

${ }^{4}$ Código de Posturas da Câmara Municipal da Capital da Província de Santa Catarina. Nossa Senhora do Desterro, 10 de maio de 1845. Capítulo 1, artigo 74.

\section{Referências}

ALMEIDA, Luciana Cristina de. Nossa Senhora do Despejo O lixo e a imundície em Nossa Senhora do Desterro no fim do Império. (décadas de 1850, 1860 e 1870). Florianópolis, 2003. Monografia em História. Universidade do Estado de Santa Catarina, Florianópolis - UDESC.

ANTONIL, André João. Cultura e Opulência do Brasil por suas Drogas e Minas. São Paulo: Melhoramentos/Brasília: INL, 1976.

ARRUDA, Gilmar. Cidades e Sertões. Bauru: EDUSC, 2000.

CARTA RÉGIA de 13 de março de 1797 Apud SOUZA, Paulo Ferreira de. Legislação Florestal. Rio de Janeiro: Diretoria de Estatística da Produção, 1934.

CAVALCANTI, Nireu. O Rio de Janeiro Setecentista: a vida e a construção da cidade da invasão francesa até a chegada da corte. Rio de Janeiro: Jorge Zahar, p. 257, 2004. 
CENCINI, Carlo. Il Paesaggio come Patrimônio: I Valori Naturali. In: Bolletino della Società Geografica Italiana. Roma. Serie XII, v. IV, 1999.

CÓDIGO DE POSTURAS DA CÂMARA MUNICIPAL DA CAPITAL DA PROVÍNCIA DE SANTA CATARINA. Nossa Senhora do Desterro, 10 de maio de 1845.

CONDE DE REZENDE. Vice Rey e Capitão General de Mar e Terra do Estado do Brasil. Ofício ao governador da Capitania de Santa Catarina Joaquim Xavier Curado. Rio de Janeiro a 14 de junho de 1801. Acervo BN.

CONDE DE REZENDE. Ofício ao Governador João Alberto de Miranda Ribeiro em 18/09/1797. Acervo: Arquivo Público do Estado de Santa Catarina - APESC.

CONDE DE REZENDE. Ofício ao Governador João Alberto de Miranda Ribeiro em 27/10/1797. Acervo: Arquivo Público do Estado de Santa Catarina - APESC.

CONDE DE REZENDE. Ofício ao Governador João Alberto de Miranda Ribeiro em 03/12/1797. Acervo: Arquivo Público do Estado de Santa Catarina - APESC.

CURADO, Joaquim Xavier. Registro de uma Sesmaria de Manoel Dutra Garcia, Funriel da Cavalaria de milícias e actual Tesoureiro dos Rendimentos da nova igreja de Nossa Senhora da Lapa do Distrito do Ribeirão. Nossa Senhora do Desterro, 28 de abril de 1804. Acervo APESC.

DEAN, Warren. A ferro e fogo: a história e a devastação da Mata Atlântica brasileira. São Paulo: Companhia das Letras, 1996.

LIMA, José Caetano de. Engenheiro Intendente da Marinha. Carta ao Senhor Dom Rodrigo de Souza Coutinho, Ministro e Secretário de Estado dos Negócios da Marinha e Domínios Ultramarinos. Rio de Janeiro, 12 de agosto de 1800. Acervo: APESC.

LORENZI, Henri. Árvores Brasileiras: manual de identificação e cultivo de plantas arbóreas nativas do Brasil. Nova Odessa: Editora Plantarum, 1992. Disponível em: www.umbuzeiro.cnip.org.br. Acesso em set. 2006.

MACHIAVELLI, Nicolò. O Príncipe. 31 ed. Rio de Janeiro: Ediouro, 1999.

McNEILL, John R. Something New Under the Sun. An Environmental History of the Twentieth-Century World. New York: Norton, 2000.

PARDAL, João Carlos. Relatório do Presidente da Província de Santa Catarina em 1838, p. 16. Disponível em: http://brazil.crl.edu/bsd/bsd. Acesso em: 08 de mar. 2007.

RIBEIRO DE ALMEIDA, João. Ensaio sobre a salubridade, estatística e pathologia da Ilha de Santa Catarina e em particular da cidade de Desterro. Desterro: Typ. de JJ. Lopes, 1864. Acervo IHGB. 


\section{Suzana Cesco}

RIBEIRO, João Alberto de Miranda. Ofício ao Conde de Rezende, apresentando relatório sobre a Ilha de Santa Catharina e demais distritos de sua jurisdição, com dados estatísticos. Desterro, 17 de novembro 1797. Acervo Biblioteca Nacional: Original, 2 doc. 130p. (códice 3,3,17).

RIBEIRO, João Alberto de Miranda. Governador da Ilha e dos demais Distritos de sua Jurisdição. Ofício ao Conde de Režende Vice Rey e Capitão General de Mar e Terra do Estado do Brasil. Villa do Desterro 11 de abril de 1798. Acervo: APESC.

RIBEIRO, João Alberto de Miranda. Ofício ao Conde de Rezende Vice Rey e Capitão General de Mar e Terra do Estado do Brasil. Villa do Desterro 22 de março de 1798. Acervo: APESC.

RIBEIRO, João Alberto de Miranda. Ofício ao Conde de Rezende, datado de n ${ }^{\circ} 17$ de 11 de abril de 1798. Acervo BN.

SOFFIATI NETTO, A. Manguezais e conflitos sociais no Brasil Colônia. In: II Encontro da Associação Nacional de Pós-Graduação e Pesquisa em Ambiente e Sociedade, 2004, Indaiatuba. Anais do II Encontro da Associação Nacional de PósGraduação e Pesquisa em Ambiente e Sociedade. Indaiatuba: ANPPAS, 2004.

VICENZI, Jacomo. Uma viagem ao Estado de Santa Catharina em 1902. Nictheroy: Tip. Amerino, 1904, p. 14. Acervo IHGB.

VIEIRA DA ROSA. Chorografia de Santa Catharina. Florianópolis: Typ. da livraria Moderna. Paschoal Simone, 1905, p. 182. Acervo IHGB.

VILELA, Valentim Antônio. Ofício do Capitão da Fragata Cisne ao Governador João Alberto de Miranda Ribeiro com Relação de consumo em 26/02/1798. Acervo: APESC.

Recebido em 25/01/2011.

Aprovado em 25/08/2011. 